\title{
Identification and expression analysis of CYP4G25 gene from the Chinese oak silkworm (Antheraea pernyi)
}

\author{
Qiuning Liu, Chaoliang Liu*, Baojian Zhu, Jia Cao, Guoqing Wei, Cen Qian, Zaigui Wang and \\ Qian Sun
}

College of Life Science, Anhui Agricultural University, Hefei 230036, People's Republic of China.

Accepted 10 May, 2011

\begin{abstract}
CYP450 plays an important role in physiological metabolism. A CYP4G25 gene of P450 family was cloned from Antheraea pernyi using reverse transcriptase-polymerase chain reaction (RT-PCR) and rapid amplification of CDNA end (RACE-PCR). Sequence analysis revealed that this gene was $2112 \mathrm{bp}$ long and has $97.5 \%$ identity with Antheraea yamamai CYP4G25. Semi-quantitative polymerase chain reaction (PCR) showed that the expression of $A$. pernyi CYP4G25 was found in various tissues with no significant changes. Sodium dodecyl sulfate polyacrylamide gel electrophoresis (SDS-PAGE) and western blot analysis demonstrated that a $63.6 \mathrm{KD}$ recombinant protein was successfully expressed in Escherichia coli cells and its expression was not remarkably changed under induction by different isopropyl- $\beta$-D-thiogalactopyranoside (IPTG) concentration.
\end{abstract}

Key words: Antheraea pernyi, CYP4G25, expression, cytochrome P450.

\section{INTRODUCTION}

Cytochrome P450s are involved in the metabolism of hormone, fatty acid, steroid, drug insecticide and phytotoxin (Mansuy et al., 1998; Hannemann et al., 2007; Isin et al., 2007; Hassanin et al., 2009). Mammal P450s play a dominant role in clearing ingested compounds and controlling the systemic levels of chemical substrates (Ding and Kaminsky, 2003; Bowles et al., 2006), and plant P450s are essential for the biosynthesis of many compounds including phenylpropanoids, lipids, phytohormones and carotenoids (Schuler and Werk, 2003; Inoue, 2004). For insects, P450s have extensive physiological functions in growth, development and reproduction through the biosynthesis or catabolism of key hormones like juvenile hormone $(\mathrm{JH})$ and 20-hydroxyecdysone (20E) (Feyereisen, 1999; Chavez et al., 2000; Warren et

*Corresponding author. E-mail: cyschx@163.com. Tel/Fax: +865515786129.

Abbreviations: RT-PCR, Reverse transcriptase-polymerase chain reaction; SDS-PAGE, sodium dodecyl sulfate polyacrylamide gel electrophoresis; IPTG, isopropyl- $\beta$-Dthiogalactopyranoside; RACE-PCR, rapid amplification of CDNA end; ORF, open reading frame; PCR, polymerase chain reaction. al., 2002; Gilbert et al., 2004; Helvig et al., 2004; Ono et al., 2006). Some P450s are found to be related with the behavioral phenotypes, insecticide metabolism or inactivation of plant toxins (Dierick and Greenspan, 2006; Wang et al., 2008; Che-Mendoza1 et al., 2009; Ai et al., 2010). For example, Drosophila CYP6G1 and CYP4E2 genes are related with dichlorodiphenyltrichloroethane (DDT) resistance (Daborn et al., 2002), while housefly CYP6D1, CYP6A1 and CYP6Z1 genes are involved in pyrethroid and organophosphate resistance (Andersen et al., 1994; Kasai and Scott, 2000; Nikou et al., 2003). Up to now, lots of P450 genes have been isolated from more than 40 insect species (Chung et al., 2009), however, the exact roles of P450s in various animals remain to be explored.

Chinese oak silkmoth Antheraea pernyi is a kind of silkproducing insects and has excellent economical values (Huang et al., 2002; Zhou and Han, 2006). In this study, a novel cytochrome P450 gene was identified from $A$. pernyi and its expression and biological function were also investigated.

\section{MATERIALS AND METHODS}

The experimental insect Chinese oak silkworm variety (Keqing) was introduced from the Sericultural Research Institute of Shandong 
Table 1. The primers used for PCR.

\begin{tabular}{ll}
\hline Primer number & Primer sequence \\
\hline F1 (-72--51) & 5'- TAAAACGTAGGTTGTCGGAGTC -3' \\
R1 (448-468) & 5'- ATTCAAGTGAAATGTGGGTGC -3' \\
F2 (162-183) & 5'- ACCACTACCGATAATAGGAAAC -3' \\
R2 (983-1003) & 5'- CAAGGAGTAAGTCAAGGAAAG -3' \\
F3 (976-996) & 5'- CGCCTAGCTTTCCTTGACTTA -3' \\
R3 (1361-1381) & 5'- GACGACGATGGAGTTTGTATG -3' \\
F4 (1363-1382) & 5'- TACAAACTCCATCGTCGTCC -3' \\
R4 (1818-1839) & 5'- GTACTTTCCCAAACTATCACC -3' \\
RC5 (386-406) & 5'- TAAGAAGTCCGTTACCGAGCC -3' \\
RC3 $(1364-1384)$ & 5'- ACAAACTCCATCGTCGTCCCG -3' \\
\hline
\end{tabular}

and reared on the leaves of oak.

\section{Total RNA extraction and cDNA synthesis}

Total RNA was extracted with TRIzol ${ }^{T M}$ Reagent (Transgene) according to the manufacture's instructions. The RevertAid ${ }^{\mathrm{TM}} \mathrm{H}$ Minus First Strand cDNA Synthesis Kit was used to synthesize cDNAs for reverse transcriptase-polymerase chain reaction (RT$P C R$ ). For rapid amplification of cDNA end (RACE-PCR), the cDNA was synthesized using SMART'M RACE cDNA Amplification Kit (Clontech) according to the manufacturer's instructions.

\section{Cloning and sequencing of Ap-CYP4G25}

Oligonucleotide primers (Table 1) were designed by Primer premier 5.0 software according to P450 sequences from Antheraea yamamai and other insects. RT-PCR was performed at $94^{\circ} \mathrm{C}$ for 5 min, followed by 35 cycles of $94^{\circ} \mathrm{C}$ for $30 \mathrm{~s}, 55^{\circ} \mathrm{C}$ for $40 \mathrm{~s}, 72^{\circ} \mathrm{C}$ for $1 \mathrm{~min}$ and a final step of $72^{\circ} \mathrm{C}$ for $10 \mathrm{~min}$. The forward primer RC3 and the reverse primer RC5 were designed for RACE-PCR. RACEPCR was carried out using the program as follows: denaturalization at $95^{\circ} \mathrm{C}$ for $5 \mathrm{~min}$ followed by 35 cycles of $94^{\circ} \mathrm{C}$ for $1 \mathrm{~min}, 60^{\circ} \mathrm{C}$ for $1 \mathrm{~min}$, and $72^{\circ} \mathrm{C}$ for $1 \mathrm{~min}$ and $30 \mathrm{~s}$. The PCR products were analyzed on $1 \%$ agarose gels, then subcloned into the pMD19-T easy cloning vector (Takara) and sequenced at Invitrogen, Shanghai.

\section{Construction of recombinant plasmids and protein expression}

Total RNA from fat body was reverse transcribed into cDNA by a First-Strand System Kit (MBI) according to the protocol. The forward primer 5'- GGCGGATCC-_ATGAGCTACACCACA-3' and reverse primer 5'- CGCCTCGAGTTATACTTTGGCTTGTT-TCT-3' (restriction enzyme sites $\overline{B a m H I}$ and $X$ hol are underlined) were designed to amplify the open reading frame (ORF) of CYP4G25 gene by PCR. The PCR product and Pet-28a vector were ligated after being digested with restriction enzymes. The recombinant plasmids (PETCYP4G25) were identified by sequencing and then transformed into competent Escherichia coli BL21 (DE3) cells (TransGen) and induced by different concentrations of isopropyl- $\beta$-D-thiogalactopyranoside (IPTG).

\section{Western blotting}

The recombinant proteins from E. coli BL21 (DE3) were subjected to Sodium dodecyl sulfate polyacrylamide gel electrophoresis (SDS-
PAGE) with $6 \%$ stacking gel and $12 \%$ separating gel, and then transferred onto a polyvinylidene difluoride membrane by an electrophoretic transfer system (Bio-Rad). Membranes were blocked with $1 \%$ bovine serum albumin (BSA) (diluted with phosphate-buffered saline containing $0.1 \%$ Tween 20 (PBST)) for 2 $\mathrm{h}$ at room temperature. Membranes were washed with PBST and subsequently incubated with primary antibodies (diluted 1:2000 with PBST) for $2 \mathrm{~h}$ at room temperature. After washing, membranes were incubated with horseradish peroxidase (HRP)-conjugated sheep anti-rabbit $\operatorname{lgG}$ antibody for $1 \mathrm{~h}$ at room temperature (Zhu and $\mathrm{Wu}, 2008$ ), and the final detection was performed with a HRP. DAB Detection Kit (Tiangen).

\section{Expression of Ap-CYP4G25 in different tissues}

Mid-intestine, silk gland, hemocytes, fat body, testis integument and ovary were dissected from the larvae at day 3 of the fifth instar and antennae was collected from adult, they were immediately frozen in liquid nitrogen and stored at $-72^{\circ} \mathrm{C}$. Semi-quantitative $\mathrm{PCR}$ was carried out with specific primers $\mathrm{F}$ : 5'-GCTCGTGCCGGCT CTCTAATCCT-3' and R: 5'-ACCGGCAGCTGTTGTATCGTGA-3' to determine the expression level of CYP4G25. The actin gene (GenBank accession number GU073316) was used as an internal reference (with primers F: 5'-TCTGGCACCCCACCTTCTAC-3' and R: 5'-CCGATTGTGATGACTTGAC-3'). The amplification program used for semi-quantitative PCR was 30 cycles of $94^{\circ} \mathrm{C}$ for $30 \mathrm{~s}$, $55^{\circ} \mathrm{C}$ for $35 \mathrm{~s}$ and $72^{\circ} \mathrm{C}$ for $40 \mathrm{~s}$.

\section{RESULTS}

\section{Cloning and sequence analysis of CYP 4 G25 cDNA}

A cDNA fragment of 2112 bp was obtained by RT-PCR and RACE-PCR. The sequence had been deposited in the GenBank database with accession number GU205081. Nucleotide sequence analysis revealed that CYP4G25 cDNA contains a 111 bp 5'-untranslated sequence, a putative ORF of $1674 \mathrm{bp}$, a $326 \mathrm{bp} \mathrm{3'-}$ untranslated region ( $\left.3^{\prime} U T R\right)$ and a putative polyadenylation signal. Based on the deduced amino acid sequences, the heme-blinding region (residues 491 to 500), I-helix domain (residues 352 to 361), K-helix domain (residues 416 to 419), C-helix domain (residues 142 to 146) and $\mathrm{N}$-terminal transmembrane anchoring signal (residues 13 to 35 ) were found using the ExPASy 
TGTOGOAGTOGACACTTCAATAGTTGGTGITAAACACAAGAAATAAAATCTTCACAAG

1 ATCACCTACACCACAGOOGAGAATGTGTGOCCAGTAGCACATTCTCTGOCATCAATCTG

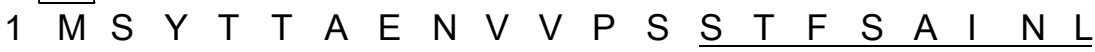

61 TTCTATGTGTGCTOGTGOOGCTCTAATCCTCTGGTACACGTACTGGAGCATTTCAAGA

$\begin{array}{lllllllllllllllllllll}21 & F & Y & V & L & L & V & P & A & L & I & L & W & Y & T & Y & W & R & I & S & R\end{array}$

The deduce $\mathrm{N}$ terminal $\mathrm{tr}$ ansmentbrane anchoring si gnal

121 CGTOGTCTCTATGAGCTGOOCGAGAGTTGOOOGAOCCAAAOCACTAOOGATAATAGGA

F2 (162-183bp)

$\begin{array}{lllllllllllllllllllll}41 & R & R & L & Y & E & L & A & E & K & L & G & G & P & K & P & L & P & I & \text { I } & G\end{array}$

181 AACGCTTTGGATTOGITGOOGTTCAGCTGACATCTTTAACAACATTATTGOGAAGAT

$61 \mathrm{~N}$ A L $E$ E $F \quad V \quad G \quad G \quad S$ A $D$ I $F$

241 CITCCATTTGATCATGAGTCAGTAGTGAGACTTTGATTGGACCTAGGTTCCTGGTATTC

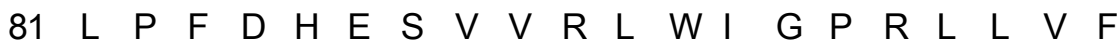

301 ATCTACGACOCTAGOGTGTGGAGTTATTCTTAGCAGTCATGTGCACATTGACAAAGT

101 I $Y$ Y $D$ P $R$ R D V E V I L S S H V H I

361 GATGAGTACAGATTTTTCAAACCTTGCCTCGTAACGGACTTCTTATAAGTACTGGACAA

RC5 (386-406bp)

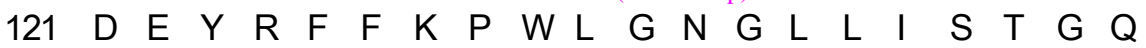
421 AAGTGOGTCTCACOGTAAACTGATTGTCOCACATTTCACTTGAATGTGTTGAGAGT R1 (448-468bp)

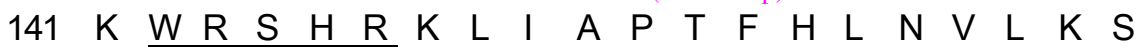
GHel ix

481 TTCATCGATTTGITCAACGCTAATTCTAGAGCTGTAGGGATAAGCTGAAGAAGGAGTCG $161 \mathrm{~F} \quad \mathrm{I} \quad \mathrm{D} \quad \mathrm{L} \quad \mathrm{F} N \mathrm{~N}$ A $N$ S R A V V D K L K $K$ 541 GCACCTTCGATTGTCATGACTACATGAGCOATGCACOGTAGAAATCTTATTAGAACT 181 G T $F$ D C C H D 601 GCAATGGGGTAAGCAAAACTACACAGGACCAGAGGGATTOGAATACGOCATGCCTGT

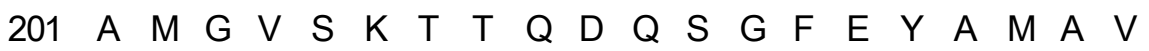
661 ATGAAGATGTGGACATCCTCCATCTCAGACACACTAAAATATGCCTCAGACCAGATTTG 221 M K $M$ M C D I L $\mathrm{H}$ L $R$ 721 CTATTTAAACTAACTGATTACCOCAAGAATCAAACCAAACTACTTGATGTCATCCACGOC $\begin{array}{lllllllllllllllllllll}241 & L & F & K & L & T & D & Y & A & K & N & Q & T & K & L & L & D & V & \text { I } & H & G\end{array}$ 781 TTAACCAAGAAGGTTATTAAGAGGAGAAGGAGAGTTCAATCACCCAAGAAACCAACT

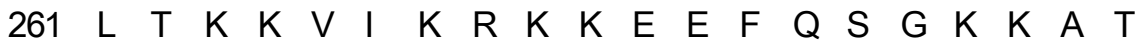
841 ATTATCOOCGACOCTAATGACGTAACAAATGAAGTCOCATCTACCAAGTCAACTTCAGTA 281 I M P E A N D V T N E V P S S K S T S V 901 GAGOCTTGCGITTGOCAGTCGTCTGACTGAAAGATGATTTGGACGTAGACGATGAT 301 E $\quad G \quad L \quad S \quad F \quad G \quad Q \quad S \quad S \quad G \quad L \quad K \quad D \quad D \quad L \quad D \quad V \quad D \quad D \quad D$ 961 GTCOOCAAAAGAAACGOCTACCTTTCCTTGACTTACTCCTTGAGAGCTCTCAAAGOGGT F3 (976-996bp) R2 (983-1003bp)

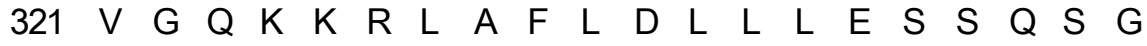

Figure 1. Nucleotide sequence and amino acid sequence of CYP4G25 from $A$. pernyi. Translation start codon (ATG) and termination codon (TAA) are boxed and the polyadenylation signals AATAAA are double-underlined.

Proteomics tools (Figure 1). Phylogenetic analysis indicated that $A$. pernyi CYP4G25 gene has $97.5 \%$ identity with $A$. yamamai CYP4G25 and $88.3 \%$ with Bombyx mori CYP4G25 (Figures 2 and 3).

\section{Protein expression and Western blotting}

The ORF of CYP4G25 was amplified by PCR and ligated to Pet-28a vector for protein expression. A recombinant 
1021 GTGGGATTACOGACGAGGAAATAAAGGAACAGTCGACACCATTATGTOGAGOGTCAC

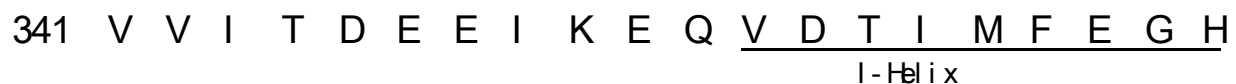

1081 GATACAACAGCTGOOGTACCAGITCTITTGTCCATGATGOCAATACACCAGCACATT

361 D $T$ T $\quad$ T A A $G \quad S \quad S \quad F \quad F \quad L \quad S \quad M \quad M \quad G \quad I \quad H \quad Q \quad H \quad$ I

1141 CAAGATAAAGTTATTGGGAGCTTGACCACATTITTGAGATTCTGATCGACOGOCACT

381 Q $D$ K V I $E$ E E L D H I $F$

1201 TTCCAGATACATTGGAGATGAAATATTGGAAAGATGCCTATGGAAACTCTTAGATTG

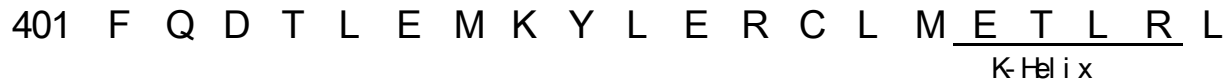

1261 TATCCAOCAGTACCTATTATCGCTOGTCAACTGAAAGAGAGATTAOCTTACOGTCAAAT

$\begin{array}{lllllllllllllllllllll}421 & Y & P & P & V & P & I & I & A & R & Q & L & K & E & E & I & T & L & P & S & N\end{array}$

1321 GSAAAGAGGTGCTATAGGAACCACT TTGGTGGGCAACATACAAACTCCATCGTCGT R3 (1361-1381bp) F4 (1363-1382bp)

$\begin{array}{llllllllllllllllllllll}441 & G & K & K & V & P & \text { I } & G & T & T & L & V & V & G & T & Y & K & L & H & R & R\end{array}$

1381 COOGATGTATATCCAAACOCACATAAATTTGACOCTGATAATTTOCTTCCTGAGOGATCT $\mathrm{RC}(1364-1384 \mathrm{bp})$

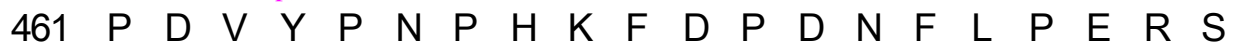

1441 GTAATOGTCACTATTACGCATTCGTCCITCTCTGTGACOCAGAGTTGGTCGGT

$\begin{array}{lllllllllllllllllllll}481 & A & N & R & H & Y & Y & A & F & V & P & F & S & A & G & P & R & S & C & V & G\end{array}$

The Heme-blinding region

1501 CGAAAATAOCOCATGITGAACCTCAAGATCATTCTGTCAACAATACTTAGGAATTOOGT

$\begin{array}{lllllllllllllllllllll}501 & \mathrm{R} & \mathrm{K} & \mathrm{Y} & \mathrm{A} & \mathrm{M} & \mathrm{L} & \mathrm{K} & \mathrm{L} & \mathrm{K} & \mathrm{I} & \mathrm{I} & \mathrm{L} & \mathrm{S} & \mathrm{T} & \mathrm{I} & \mathrm{L} & \mathrm{R} & \mathrm{N} & \mathrm{F} & \mathrm{R}\end{array}$

1561 GTCTACTCAGATCTCACTGAATCGOATTTCAAACTTCAACCAGATATAATTTTGAAACGA

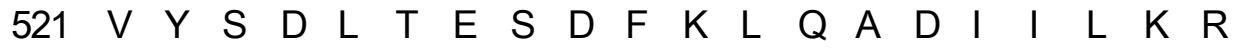

1621 GCTGAAGGTTTCAAAGTTOGTCTACAACCACGTAAGAAACAAGCCAAAGTATAA

$\begin{array}{llllllllllllllllll}541 & A & E & G & F & K & V & R & L & Q & P & R & K & K & Q & A & K & V\end{array}$

GAAGGTTAACTATTOCTATACCATCATCTTTACGCTATAATGTAAATGTACAATGOCTAA ATTGTCAGAGACATTCGOGTTTGTGATACTAGAACTGAATAAATTATTATTTCITTATT ATTAAAAGGATGITGITTAAAATGGTGATAGITITGOGAAGTACAAATAAAGGACA R4 (1818-1839bp)

GGGGTATTGTTGCTCAAGAACATTAAGCTAATCAATTTGTTTTTTGTTTGAA TTTGTAAATAAGTAGTTAAATTATATTGGTTGTAGACTTTCACTATATTGACA TATTAAACGTGATGTTCAAAGTAAAAAAAAAAAAAAAAAAAAAA

Figure 1. Continued.

protein with a molecular weight of about $63 \mathrm{kDa}$ was detected by SDS-PAGE and the expression was not influenced by different IPTG concentrations (Figure 4).

Western blot analysis of recombinant protein showed that a consensus $63 \mathrm{kDa}$ protein band was detected using anti-His antibody, while there was none in the control group (Figure 5). All this indicate the successful expression of the recombinant CYP4G25 protein in $E$. coli BL21 (DE3) cells.

\section{Expression of Ap-CYP4G25 in different tissues}

Semi-quantitative PCR was carried out to detect the expression of CYP4G25. The CYP4G25 gene ubiquitously expressed in fat body, integument, midintestine, hemocytes, silk glands, antennae, testis and ovary with no obvious difference (Figure 6). These results suggest that the CYP4G25 plays an important role in the growth and development of $A$. pernyi.

\section{DISCUSSION}

In this study, a full-length cDNA encoding CYP $4 G 25$ gene was identified from $A$. pernyi. The cDNA is $2112 \mathrm{bp}$ long and contains an open reading frame of $1674 \mathrm{bp}$. The predicted protein consists of 557 amino acids with a 


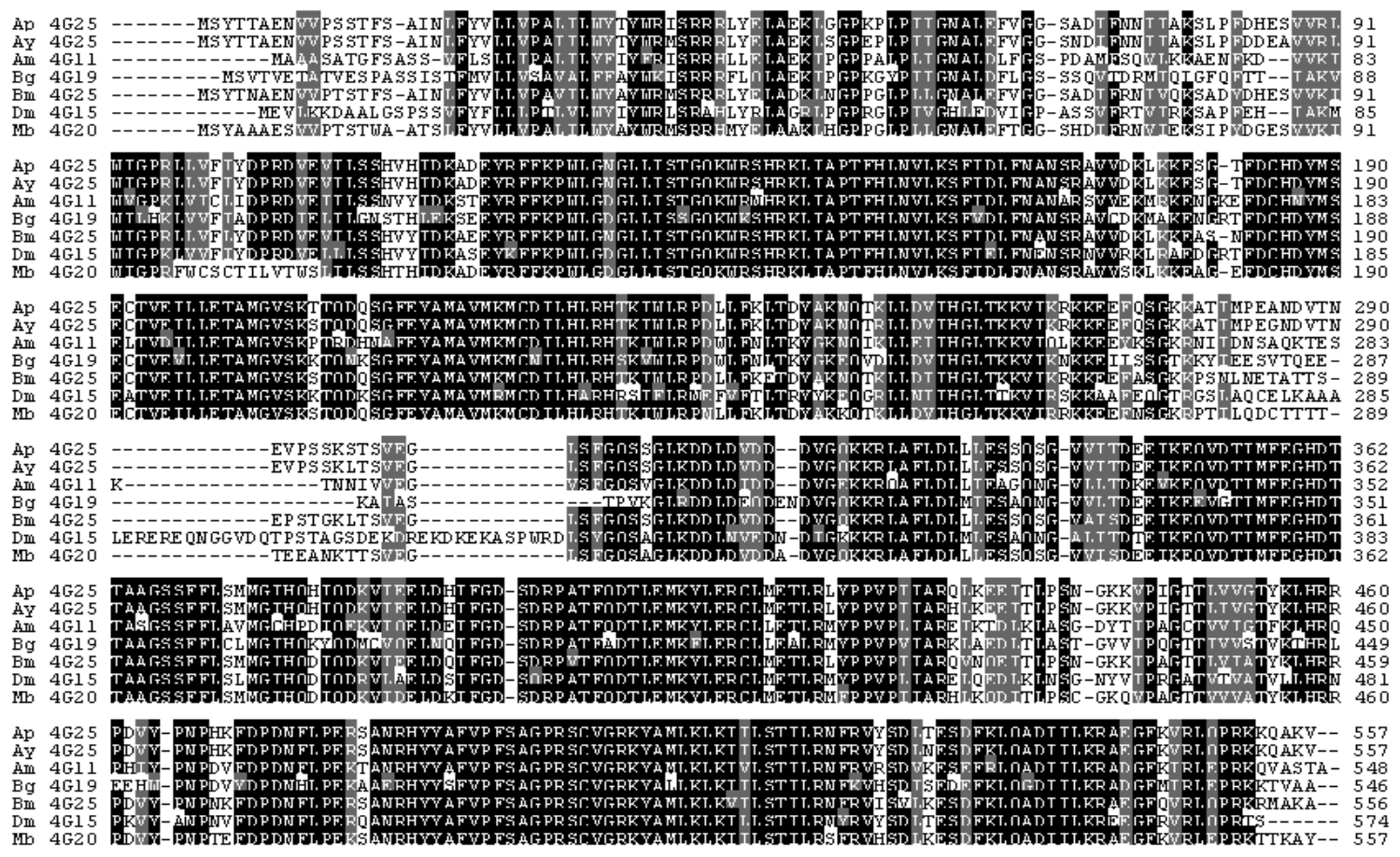

Figure 2. Sequence alignment of the A. pernyi CYP4G25 proteins with its homologues. The CYP proteins from $A$. yamamai CYP4G25 (BAD81026), Apis mellifera CYP4G11 (ABB36785), Blattella germanica CYP4G19 (AAO20251), B. mori CYP4G25 (ABF51415), Drosophila melanogaster CYP4G15 (AAF76522) and Manduca sexta CYP4G20 (ADE05582) were included.

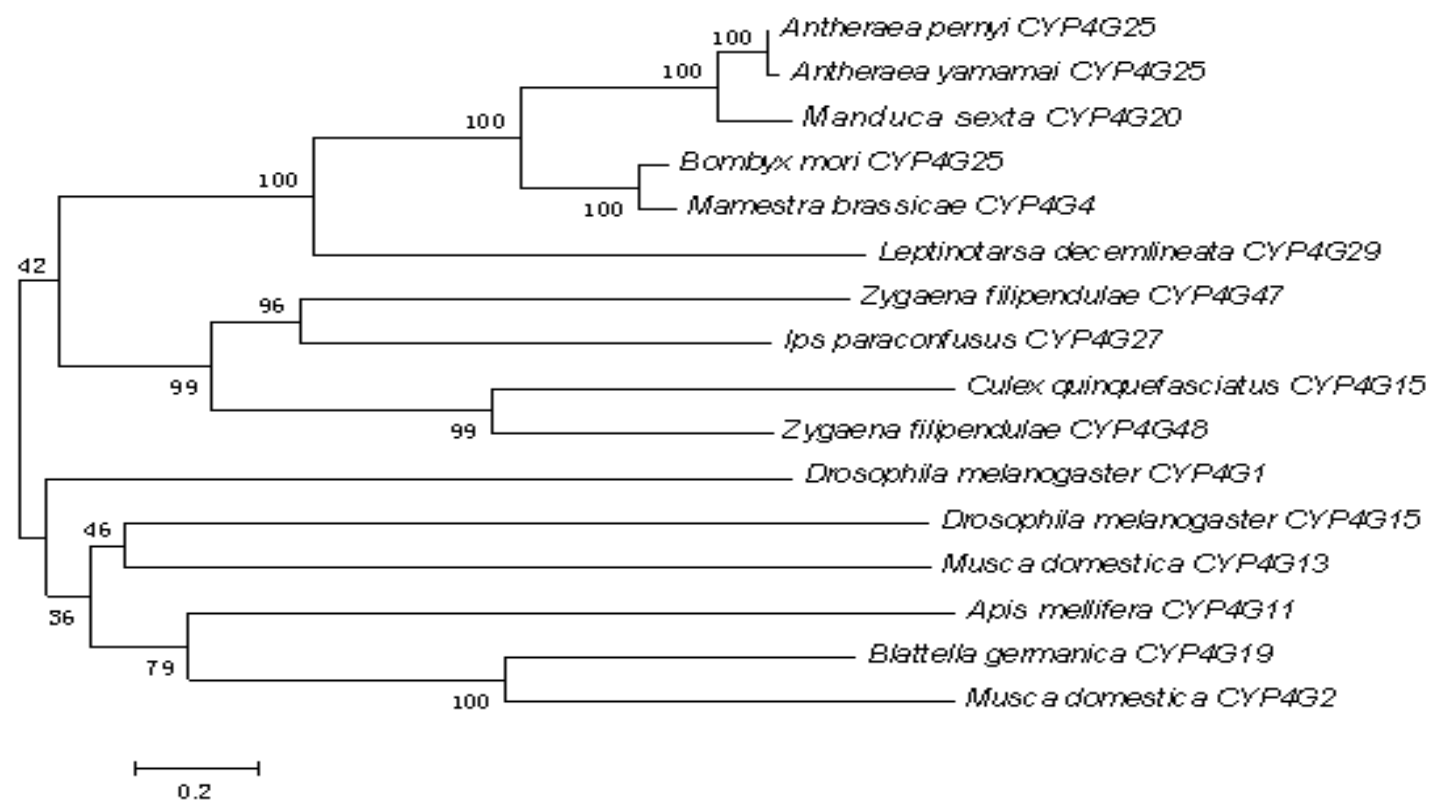

Figure 3. Phylogenetic analysis was performed by MEGA (version 4.0) program based on the CYP4G25 amino acid sequences from various insects. The phylogenetic tree was constructed using the neighborjoining algorithm method and bootstrap values (1000 repetitions) of the branches are indicated. The CYP proteins from other organisms are: A. yamamai CYP4G25 (BAD81026), A. mellifera CYP4G11 (ABB36785), B. germanica CYP4G19 (AAO20251), B. mori CYP4G25 (ABF51415), D. melanogaster CYP4G1 (ABY20430) and CYP4G15 (AAF76522), M. sexta CYP4G20 (ADE05582) and Mamestra brassicae CYP4G (AAR26517), Culex quinquefasciatus CYP4G15 (EDS33030), Leptinotarsa decemlineata CYP4G29 (AAZ94273), Zygaena filipendulae CYP4G47 (ACZ97413) and CYP4G48 (ACZ97414), Ips paraconfusus CYP4G27 (ABF06553), Musca domestica CYP4G2 (ABV48808) and CYP4G13 (AAK40120). 


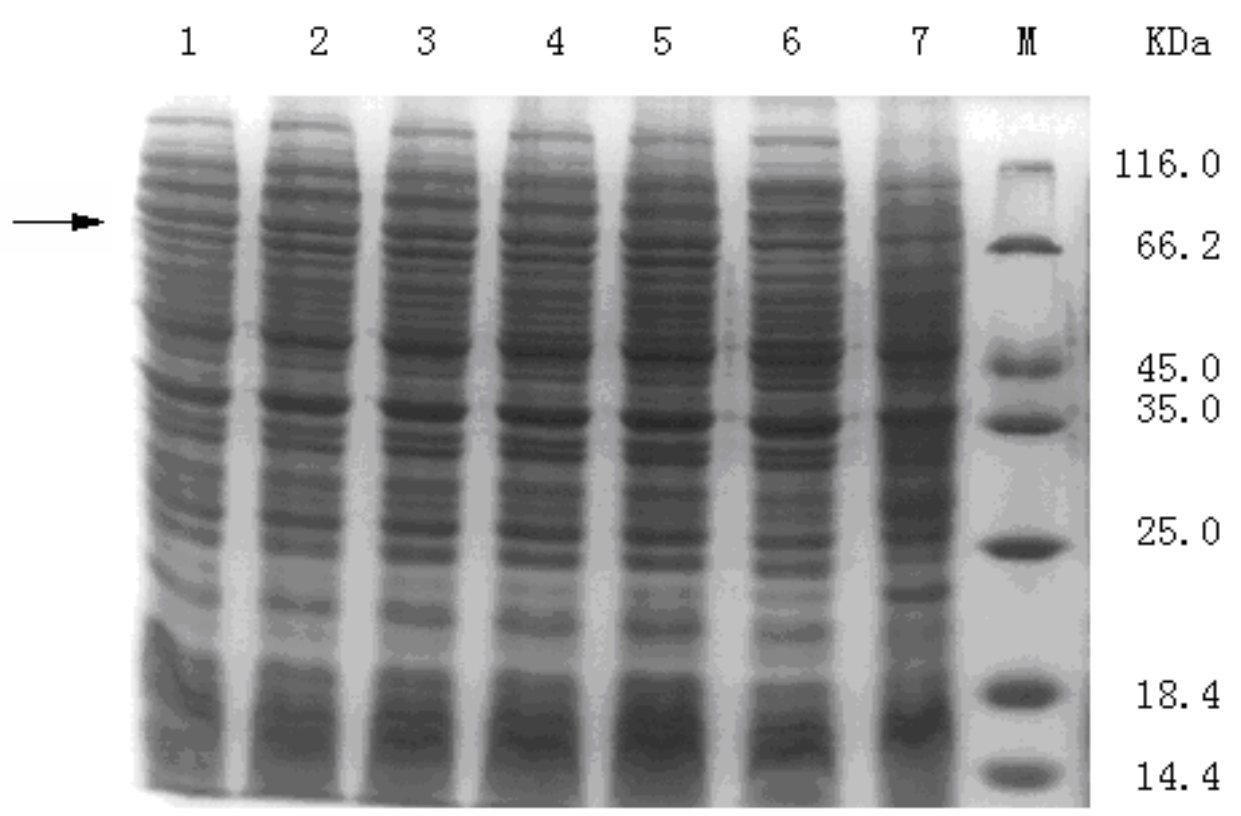

Figure 4. Analysis of recombinant Ap-CYP4G25 protein on 12\% SDS-PAGE gels. The protein amount used for SDS-PAGE was $30 \mu \mathrm{g}$ in each lane and the gels were revealed by Coomassie blue R-250 staining. Bacterial proteins were collected after $4 \mathrm{~h}$ induction with different IPTG concentration. Lanes 1 to 5 , after induction with $0.2,0.4,0.6,0.8$ and $1.0 \mathrm{mM} \mathrm{IPTG}$, respectively; Lane 6, before induction; Lane 7, E. coli BL21(DE3); M, molecular weight marker.

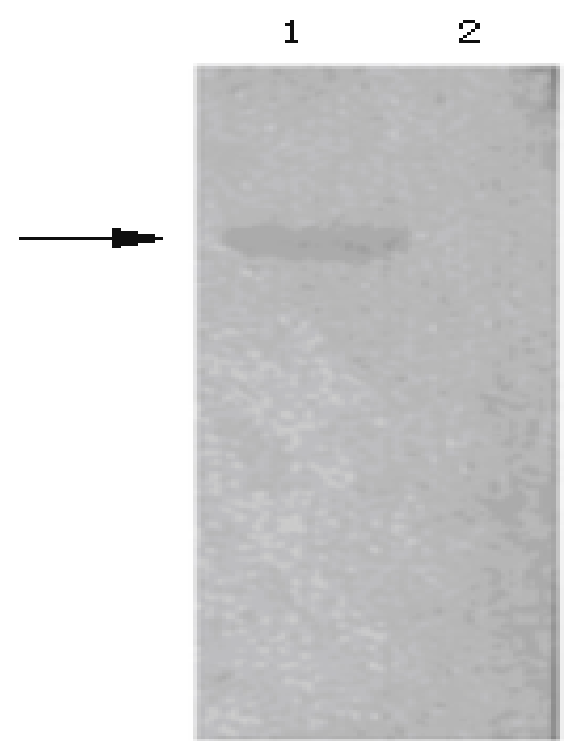

Figure 5. Western blot analysis of recombinant proteins with anti His-tag antibody. A total of $30 \mu \mathrm{g}$ recombinant protein was used for Western blotting and a protein band with a molecular mass of about $63.6 \mathrm{kDa}$ was detected by Western blotting using anti His-tag antibody. No immunoreactive band was found in the control group. Lane 1, After IPTG induction; lane 2 , no IPTG induction. 

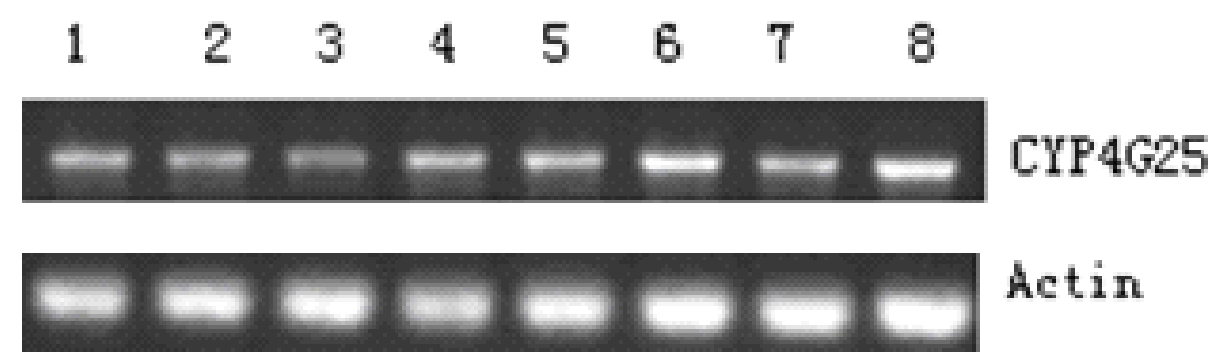

Figure 6. Expression analysis of Ap-CYP4G25 by semi-quantitative PCR. Lanes 1 to 8 , expression of Ap-CYP4G25 in mid-intestine, silk gland, hemocytes, fat body, testis integument, ovary and antennae, respectively. The expression of Ap-actin was used as a control.

calculated molecular mass of $63.6 \mathrm{kDa}$, which is somewhat larger than the size of other known vertebrate and invertebrate P450s (55 to $60 \mathrm{kDa}$ ). Phylogenetic analysis indicated that $A$. pernyi CYP4G25 was highly homologous to that of $A$. yamamai and a heme-binding domain (FXXGXRXCXG) which serves as fifth ligand to the heme iron and a $K$ helix was found in the protein sequence (Werk and Feyereisen, 2000).

The CYP4 is a member of the most ancient P450s, and many CYP4 subfamilies have been identified in arthropods and their enzymatic activities had been determined (Snyder et al., 1995; Pittendrigh et al., 1997). According to the reports, the new gene CYP4G20 may be associated with the diversity of odorants (Maibeche et al., 2005), while CYP4G15 is probably important for the metabolism of endogenous compounds (Maibeche et al., 2000), and CYP4G25 in A. yamamai is associated with diapause (Yang et al., 2008). Furthermore, P450s are involved in the detoxification of many xenobiotics (Feyereisen, 1999; Isin et al., 2007). However, the exact biological function of CYP4G25 in $A$. pernyi remains unknown.

All together, A. pernyi CYP4G25 was characterized in this experiment and it was ubiquitously expressed in all examined tissues, and the prokaryotic expression of this protein was also successfully performed, we hope these results will provide some information for further studies.

\section{ACKNOWLEDGEMENT}

This work was supported by the earmarked fund for Modern Agro-industry Technology Research System.

\section{REFERENCES}

Ai JW, Yu QY, Cheng TC, Dai FY, Zhang XS, Zhu Y, Xiang ZH (2010). Characterization of multiple CYP9A genes in the silkworm, Bombyx mori. Mol. Biol. Rep., 37: 1657-1664.

Andersen JF, Utermohlen JG, Feyereisen R (1994). Expression of house fly CYP6A1 and NADPH-cytochrome P450 reductase in Escherischia coli and reconstitution of an insecticide- metabolizing
P450 system. Biochemistry, 33: 2171-2177.

Bowles J, Knight D, Smith C, Wilhelm D, Richman J, Mamiya S, Yashiro $\mathrm{K}$, Chawengsaksophak K, Wilson MJ, Rossant J, Hamada $\mathrm{H}$, Koopman P (2006). Retinoid signaling determines germ cell fate in mice. Science, 312: 596-600.

Chavez VM, Marques G, Delbecque JP, Kobayashi K, Hollingsworth M, Burr J, Natzle JE, O'Connor MB (2000). The Drosophila disembodied gene controls late embryonic morphogenesis and codes for a cytochrome P450 enzyme that regulates embryonic ecdysone levels. Development, 127: 4115-4126.

Che-Mendoza1 A, Penilla RP, Rodrigue DA (2009) Insecticide resistance and glutathione S-transferases in mosquitoes: A review. Afr. J. Biotechnol., 8(8): 1386-1397.

Chung H, Sztal T, Pasricha S, Sridhar M, Batterham P, Daborn PJ (2009). Characterization of Drosophila melanogaster cytochrome P450 genes. Proc.Natl.Acad.Sci.USA., 106: 5731-5736.

Daborn PJ, Yen JL, Bogwitz MR, Le Goff G, Feil E, Jeffers S, Tijet N, Perry T, Heckel D, Batterham P, Feyereisen R, Wilson TG, ffrenchConstant $\mathrm{RH}$ (2002). A single $\mathrm{P} 450$ allele associated with insecticide resistance in Drosophila. Science, 297: 2253-2256.

Dierick HA, Greenspan RJ(2006). Molecular analysis of flies selected for aggressive behavior. Nat. Genet., 38: 1023-1031.

Ding X, Kaminsky L(2003). Human extrahepatic cytochromes P450: function in xenobiotic metabolism and tissue-selective chemical toxicity in the respiratory and gastrointestinal tracts. Annu. Rev. Pharmacol. Toxicol., 43: 149-173.

Feyereisen R (1999). Insect P450 enzymes. Annu. Rev. Entomol., 44: 507-533.

Gilbert LI(2004). Halloween genes encode P450 enzymes that mediate steroid hormone biosynthesis in Drosophila melanogaster. Mol. Cell. Endocrinol., 215: 1-10.

Hannemann F, Bichet A, Ewen KM, Bernhardt R (2007). Cytochrome P450 systems-biological variations of electron transport chains. Biochim. Biophys. Acta., 1770: 330-344.

Hassanin AAl, Kaminishi Y, Osman MMM, Abdel-Wahad ZH, El-Kady $\mathrm{MAH}$, Itakura T (2009). Cloning and sequence analysis of benzo-apyreneinducible cytochrome P450 1A in Nile tilapia (Oreochromis niloticus). Afr. J. Biotechnol., 8(11): 2545-2553.

Helvig C, Koener JF, Unnithan GC, Feyereisen R (2004). CYP15A1, the cytochrome P450 that catalyzes epoxidation of methyl farnesoate to juvenile hormone III in cockroach corpora allata. Proc. Natl. Acad. Sci. USA., 101: 4024-4029.

Huang YJ, Kobayashi J, Yoshimura T(2002). Genome mapping and gene analysis of Antheraea pernyi nucleopolyhedrovirus for improvement of baculovirus expression vector system. J. Biosci. Bioeng., 93: 183-191.

Inoue K (2004). Carotenoid hydroxylation-P450 finally! Trends. Plant. Sci., 9: 515-517.

Isin EM, Guengerich FP(2007). Complex reactions catalyzed by cytochrome P450 enzymes. Biochim. Biophys. Acta., 1770: 314-329.

Kasai S, Scott JG (2000). Overexpression of cytochrome P450 CYP6D1 
is associated with monooxygenase-mediated pyrethroid resistance in houseflies from Georgia. Pestic. Biochem. Physiol., 68: 34-41.

Maibeche CM, Monti DL, Aragon S, Dauphin VC (2000). A new cytochrome P450 from Drosophila melanogaster, CYP4G15, expressed in the nervous system. Biochem. Bioph. Res., 273: 11321137.

Maibeche CM, Merlin C, Francois MC, Porcheron P, Jacquin JE (2005). P450 and P450 reductase cDNAs from the moth Mamestra brassicae: cloning and expression patterns in male antennae. Gene., 346: 195-203.

Mansuy $\mathrm{D}(1998)$. The great diversity of reactions catalyzed by cytochromes P450. Comp. Biochem. Physiol. C-Pharmacol. Toxicol. Endocrinol., 121: 5-14.

Nikou D, Ranson H, Hemingway J (2003). An adult-specific CYP6 P450 gene is over- expressed in a pyrethroid-resistant strain of the malaria vector, Anopheles gambiae. Gene, 318: 91-102.

Ono H, Rewitz KF, Shinoda T, Itoyama K, Petryk A, Rybczynski R, Jarcho M, Warren JT, Marqués G, Shimell MJ, Gilbert LI, O'Connor MB (2006). Spook and Spookier code for stage-specific components of the ecdysone biosynthetic pathway in Diptera. Dev. Biol., 298: 555570.

Pittendrigh B, Aronstein K, Zinkovski E, Andreev O, Campbell B, Daly J, Trowell S, ffrench-Constant RH (1997). Cytochrome P450 genes from Helicoverpa armigera: Expression in a pyrethroid-susceptible and resistant strain. Insect. Biochem. Mol. Biol., 27: 507-512.

Schuler MA, Werk RD (2003). Functional genomics of P450s. Annu. Rev. Plant Biol., 54: 629-667.
Snyder MJ, Stevens JL, Andersen JF, Feyereisen R (1995). Expression of Cytochrome P450 Genes of the CYP4 Family in Midgut and Fat Body of the Tobacco Hornworm, Manduca sexta. Arch.Biochem.Biophys., 321: 13-20.

Wang L, Dankert H, Perona P, Anderson J (2008). A common genetic target for environmental and heritable influences on aggressiveness in Drosophila. Proc. Natl. Acad. Sci. USA., 105: 5657-5663.

Warren JT, Petryk A, Marques G, Jarcho M, Parvy JP, Dauphin-villemant C, O'Connor MB, Gilbert L (2002). Molecular and biochemical characterization of two P450 enzymes in the ecdysteroid-ogenic pathway of Drosophila melanogaster. Proc. Natl. Acad. Sci. USA., 99: 11043-11048.

Werk RD, Feyereisen R (2000). Cytochromes P450: a success story. Genome. Biol., 1: 1-9.

Yang P, Tanaka H, Kuwano E, Suzuk K (2008). A novel cytochrome P450 gene (CYP4G25) of the silk moth Antheraea yamamai: Cloning and expression pattern in pharate first instar larvae in relation to diapause. J. Insect. Phys., 54: 636-643.

Zhou J, Han DX (2006). Safety evaluation of protein of silkworm (Antheraea pernyi) pupae. Food.Chem. Toxicol., 44: 1123-1130.

Zhu BJ, Wu XZ (2008). Identification of outer membrane protein ompR from rickettsia-like organism and induction of immune response in Crassoatrea ariakensis. Mol. Immunol., 45: 3198-3204. 